\author{
HERMAEA \\ GERMANISTISCHE FORSCHUNGEN \\ NEUE FOLGE \\ HERAUSGEGEBEN VON \\ JOACHIM HEINZLE UND KLAUS-DETLEF MÜLLER \\ BAND 101
}





\title{
ULRIKE DEDNER
}

\section{Deutsche Widerspiele der Französischen Revolution}

\author{
Reflexionen des Revolutionsmythos \\ im selbstbezüglichen Spiel von Goethe bis Dürrenmatt
}

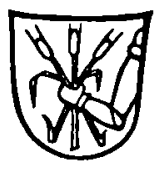

MAX NIEMEYER VERLAG

TÜBINGEN 2003 
Meinem Mann Christopher

und meinen Eltern Christel und Henning Krauß

D21

Bibliografische Information der Deutschen Bibliothek

Die Deutsche Bibliothek verzeichnet diese Publikation in der Deutschen Nationalbibliografie; detaillierte bibliografische Daten sind im Internet über $h t t p: / / d n b$.ddb.de abrufbar.

ISBN 3-484-15101-3 ISSN 0440-7164

(C) Max Niemeyer Verlag GmbH, Tübingen 2003

http://www.niemeyer.de

Das Werk einschließlich aller seiner Teile ist urheberrechtlich geschützt. Jede Verwertung außerhalb der engen Grenzen des Urheberrechtsgesetzes ist ohne Zustimmung des Verlages unzulässig und strafbar. Das gilt insbesondere für Vervielfältigungen, Übersetzungen, Mikroverfilmungen und die Einspeicherung und Verarbeitung in elektronischen Systemen. Printed in Germany.

Gedruckt auf alterungsbeständigem Papier.

Satz: Johanna Boy, Brennberg

Druck: Gulde Druck GmbH, Tübingen

Buchbinder: Geiger, Ammerbuch 